\title{
A comprehensive review on non-edible woody oil- based biodiesel: composition, production, properties and emissions
}

\author{
Ying-Xuan $\mathrm{Li}^{* 1}$, and Yun-Qi Zhang, ${ }^{2 *}$ \\ ${ }^{1}$ Zibo Experimental High School, Zibo, China \\ ${ }^{2}$ National Energy R\&D Center for Non-food Biomass Materials, Beijing Forestry University, Beijing, China
}

\begin{abstract}
With the continuous increase of world's population, rapid development of industrialization and urbanization, and rapid growth of economy, the fossil fuel consumption is also increasing continuously to meet growing energy demand. The unsustainability of fossil fuels and the issues of national energy security make it very urgent to develop the appropriate and sustainable replacement for fossil fuels. Biodiesel is one of appropriate alternatives for diesel engine due to its renewable and eco-friendly nature. This greener fuel has been used in many countries across the continents in a blending range up to $20 \%$ with petrodiesel. However, the high biodiesel production cost is still a major obstacle to market acceptance. Non-edible woody oils can be considered as low-cost substitutions for traditional edible vegetable oils for biodiesel production. In order to make biodiesel into reality in much wider scope, a growing number of relevant researches focused on: (1) evaluating the biodiesel properties; (2) optimizing the production process; and (3) assessing the environmental impact. This article reviews these three aspects in order to reflect the research status and development potential of non-edible woody oil-based biodiesel.
\end{abstract}

\section{Introduction}

Energy is the driving force of the socio-economic growth of the society. However, with the further increase of world's population, energy demand is also rising sharply. The excessive exploitation and consumption of fossil energy continue to aggravate the environmental degradation and energy shortage. Partial replacement of fossil energy by renewable energy is considered to be a feasible solution which harmoniously correlate with sustainable development, energy conservation and environmental protection. Among the renewable energy sources, bioenergy has the following advantages: (1) extensive sources and large reserves; (2) renewability; (3) different from wind, water, geothermal and tidal energy, bioenergy is less affected by geographical distribution; (4) various derivatives including solid, liquid and gas products; (5) safe storability and ease in handling and transport; (6) biodegradability. In recent years, bioenergy has attracted more and more attention. As an important aspect of bioenergy utilization, the development of biodiesel from vegetable oil has become a hot topic, because biodiesel has similar fuel characteristics to diesel. Biodiesel has almost no sulfur and aromatic compounds, and has comparable thermal efficiency vis-a-vis diesel fuel. Moreover, biodiesel is considered to be carbon neutral since the $\mathrm{CO}_{2}$ released into the atmosphere during combustion has been reused for plant growth ${ }^{[1]}$, and contribute much less to global warming than its fossil-oriented counterpart ${ }^{[2]}$.

Biodiesel is defined by ASTM as a fuel comprised of long-chain fatty acid alkyl esters ${ }^{[3]}$ which formed by the process of chemical known as transesterification and esterification. According to European Academies Science Advisory Council (EASAC) 2012, biodiesel is classifed in four generations based on the type of feedstocks. Biodiesel that produced from edible oils termed as first generation, non-edible oils as second generation, and waste and algal oils as third generation oil, which naturally is renewal and also finds locally ${ }^{[4]}$. Fourth generation biodiesel includes synthetic biology technology and research on this is still on infancy level. Among these different types of biodiesel, the 2 nd biodiesel were seemed closer to the properties of standard diesel ${ }^{[5]}$. Choosing non-edible woody oils to produce biodiesel can also help to reduce the production cost and develop marginal land. In addition, the development of woody plants for biodiesel has more important ecological significance, because woody plants have stronger carbon sequestration capacity. Comprehensive consideration of environmental preservation, exhaust emissions, production costs and engine performance, non-edible woody biodiesel is more suitable for priority development at present ${ }^{[6]}$.

For the healthy development of biodiesel industry, it is indispensible to evaluate the biodiesel properties, biodiesel production processes, and exhaust emissions. Thus in this article, the authors made a meticulous effort to systematically review these three aspects on biodiesel fuels from the published literature of various resources. 
The detailed contents of each part are shown in the following sections.

\section{Physicochemical properties of biodiesel from various feedstocks}

The fatty acid compositions of raw oils are mainly affected by tree species and their growing environment. Different fatty acid compositions eventually lead to the difference of biodiesels properties. The main physicochemical properties of these 26 biodiesels ${ }^{[7,8,9,10,11]}$ were shown in Table 1 .

Density plays a crucial role in influencing the efficiency of the fuel atomization in airless combustion systems and in determining the fuel injection property ${ }^{[12]}$. From Table 1, Simmondsia chinesis biodiesel had the highest density $\left(920.0 \mathrm{~kg} \cdot \mathrm{m}^{-3}\right)$, while that of Schleichera oleosa biodiesel was the lowest $\left(856.5 \mathrm{~kg} \cdot \mathrm{m}^{-3}\right)$.

Caloric value $(\mathrm{CV})$ and cetane number $(\mathrm{CN})$ are the main indexes to indicate the combustion performance. The higher the calorific value, the better the combustion performance. Although the $\mathrm{CV}$ of biodiesel is lower than that of petrodiesel $(43 \mathrm{MJ} / \mathrm{kg})$, biodiesel burns more sufficiently and emits less black smoke due to its high oxygen content. As shown in Table 1, Mesua ferrea biodiesel and Simmondsia chinesis biodiesel had the highest $\mathrm{CV}$, while that of Madhuca indica biodiesel was the lowest. Biodiesel has a higher $\mathrm{CN}$ value than petrodiesel. A higher $\mathrm{CN}$ value means shorter ignition delay, better ignition, higher thermal efficiency and less fuel consumption. Among these biodiesels, Moringa oleifera biodiesel, Ceiba pentandra biodiesel and Firmiana platanifolia biodiesel had the higher $\mathrm{CN}$ values which were 66.0, 58.4 and 58.2, respectively. The $\mathrm{CN}$ values of Vernicia montana biodiesel and Sapium sebiferum biodiesel were lower because both raw oils contained more polyunsaturated fatty acids.
Kinematic viscosity (KV) and cold filter plugging point (CFPP) are commonly used as major indicator of fluidity. The KV value decreases with the increase of temperature. High or low KV value will lead to incomplete combustion and reduce engine efficiency. Vernicia montana biodiesel had the highest KV value due to the high content of eleostearic acid. Sapium sebiferum biodiesel and Cornus wilsoniana biodiesel had the lower $\mathrm{KV}$ value due to the high unsaturation degree. The CFPP refers to the temperature at which a fuel jams a filter due to the formation of crystalline agglomerates ${ }^{[1]}$. The lowtemperature fluidity and filtration characteristics of fuel becomes worse with the increase of CFPP. Because of the high content of long-chain saturated fatty acid in the raw oils, Terminalia catappa biodiesel, Calophyllum inophyllum biodiesel, Azadirachta indica biodiesel and Moringa oleifera biodiesel had the high CFPP and poor flow properties. Prunus sibirica biodiesel, Amygdalus pedunculata biodiesel and Sapium sebiferum biodiesel all had lower CFPP value and better flow properties at cold temperatures as their higher unsaturation degree.

Storage stability is another important property for fuel. Generally, the flash point (FP) range of biodiesel is higher than that of petrodiesel, which makes biodiesel safer for transport, handling, and storage purpose ${ }^{[12]}$. Athough the FP of Mesua ferrea biodiesel $\left(112.0^{\circ} \mathrm{C}\right)$ is lower than other biodiesels listed in Table 1, the FP of these biodiesels are all exceeded the minimum values specified by ASTM D6751-2018 ( $\left.\geq 93^{\circ} \mathrm{C}\right)$ and EN 14214:2014 ( $\left.\geq 101^{\circ} \mathrm{C}\right)$. The oxidation stability (OS) of biodiesel always be used for indicating the oxidation degree. Oxidation occurs due to the presence of heat, traces of metal, peroxides, light, unsaturated fatty acid chains, and the double bonds, which react with oxygen as soon as it is exposed to air, so biodiesels are more susceptible to deteriorating easily during the storage period than petrodiesel ${ }^{[1]}$.

Table 1. Biodiesel properties from various feedstocks

\begin{tabular}{|c|c|c|c|c|c|c|c|}
\hline Feedstocks & $\begin{array}{c}\text { Density } \\
\left(15^{\circ} \mathrm{C} ; \mathrm{kg} \cdot \mathrm{m}^{-3}\right)\end{array}$ & $\begin{array}{c}\mathrm{CV} \\
\left(\mathrm{MJ} \cdot \mathrm{kg}^{-1}\right)\end{array}$ & $\mathrm{CN}$ & $\begin{array}{c}\mathrm{KV} \\
\left(40^{\circ} \mathrm{C} ; \mathrm{mm}^{2} \cdot \mathrm{s}^{-1}\right)\end{array}$ & $\begin{array}{l}\text { CFPP } \\
\left({ }^{\circ} \mathrm{C}\right) \\
\end{array}$ & $\begin{array}{l}\mathrm{FP} \\
\left({ }^{\circ} \mathrm{C}\right)\end{array}$ & $\begin{array}{c}\text { OS } \\
\left(110^{\circ} \mathrm{C} ; \mathrm{h}\right)\end{array}$ \\
\hline Terminalia catappa & $879.0^{\mathrm{a}}$ & 38.5 & 57.1 & 4.3 & 12.0 & - & 2.1 \\
\hline Terminalia belerica & 882.8 & 39.2 & 53.0 & 5.2 & - & - & - \\
\hline Jatropha curcas & 873.8 & 40.0 & 55.0 & 4.6 & 0.1 & 158.8 & 3.2 \\
\hline Pistacia chinensis & 880.0 & - & 51.3 & 4.3 & -3.0 & - & 4.2 \\
\hline Calophyllum inophyllum & 874.9 & 39.6 & 56.4 & 5.0 & 10.3 & 157.4 & 9.8 \\
\hline Firmiana platanifolia & $879.0^{\mathrm{a}}$ & - & 58.2 & 4.3 & 3.0 & 155.0 & 13.3 \\
\hline Cerbera manghas & 869.7 & 40.1 & - & 4.9 & 4.0 & 159.5 & 8.2 \\
\hline Madhuca indica & 863.8 & 36.9 & 56.7 & 4.7 & 6.0 & 150.6 & 2.1 \\
\hline Azadirachta indica & 879.3 & 39.8 & 56.6 & 5.1 & 11.0 & 162.5 & 7.1 \\
\hline Schleichera oleosa & 856.5 & 41.8 & 50.6 & 4.3 & -4.0 & 136.5 & 7.2 \\
\hline
\end{tabular}




\begin{tabular}{|c|c|c|c|c|c|c|c|}
\hline Prunus sibirica & 876.6 & - & 49.1 & 4.3 & -14.3 & 177.5 & 2.7 \\
\hline Amygdalus pedunculata & 877.0 & - & 49.2 & 4.7 & -11.0 & 169.0 & 2.2 \\
\hline Sapindus mukorossi & 879.0 & 40.0 & 54.0 & 4.5 & 5.0 & 147.0 & 3.9 \\
\hline Manilkara zapota & 875.0 & 37.2 & 52.0 & 4.7 & - & 174.0 & - \\
\hline Mesua ferrea & 898.0 & 42.2 & 54.0 & 6.2 & - & 112.0 & - \\
\hline Pongamia pinnata & 892.0 & 40.8 & 55.9 & 5.1 & -7.0 & 164.7 & 2.5 \\
\hline Simmondsia chinesis & 920.0 & 42.2 & 55.0 & 5.2 & -10.0 & 186.0 & - \\
\hline Moringa oleifera & 877.4 & 40.1 & 66.0 & 5.0 & 15.5 & 206.0 & 2.7 \\
\hline Croton megalocarpus & 889.9 & 39.5 & 50.6 & 4.4 & -4.0 & 185.5 & 1.1 \\
\hline Sapium sebiferum & 900.0 & - & 40.2 & 3.7 & -10.5 & 137.0 & 0.7 \\
\hline Ceiba pentandra & 871.2 & 40.5 & 58.4 & 4.4 & 1.0 & 161.4 & 4.3 \\
\hline Hevea brasiliensis & 875.2 & 37.3 & 50.4 & 5.2 & -1.0 & 147.1 & 8.1 \\
\hline Xanthoceras sorbifolia & 880.5 & 39.7 & 52.4 & 4.4 & -3.0 & 165.0 & 1.7 \\
\hline Vernicia montana & 903.0 & - & 38.3 & 7.6 & -11.0 & 176.0 & 0.4 \\
\hline Sterculia foetida & 874.2 & 40.1 & 54.8 & 5.6 & -2.5 & 161.4 & 3.4 \\
\hline Cornus wilsoniana & $897.0^{\mathrm{a}}$ & - & 49.0 & 3.8 & 0.0 & 147.0 & 0.6 \\
\hline
\end{tabular}

Note: a measuring temperature was $20^{\circ} \mathrm{C}$

\section{Biodiesel production processes}

\subsection{Catalytic technologies}

\subsubsection{Homogeneous alkali and acid-catalyzed transesterification}

At present, homogeneous catalysis is mainly used in industrial biodiesel production, and $\mathrm{NaOH}$ or $\mathrm{KOH}$ is most commonly used as alkali catalyst. Though the alkalicatalyzed transesterification of vegetable oils proceeds faster than the acid-catalyzed reaction, the base-catalyzed reaction is more sensitive to the purity of reactant. In order to prevent saponification and hydrolysis during the reaction, free fatty acids (FFAs) and water content of the feed should be below $0.5 \mathrm{wt} . \%$ and $0.05 \mathrm{wt} . \%$, respectively ${ }^{[13]}$. Alkaline metal oxides $\left(\mathrm{CH}_{3} \mathrm{ONa}\right.$, and $\left.\mathrm{CH}_{3} \mathrm{OK}\right)$ are considered to be the most active catalysts and could be used as substitute for $\mathrm{NaOH}$ or $\mathrm{KOH}$, since they have very high conversion rates in short time even when applied at lower concentration ${ }^{[14]}$. Homogeneous acid-catalyzed reaction is about 4000 times slower than the homogeneous base-catalyzed reaction. However, the performance of the acid catalyst is not strongly affected by FFAs in the feedstocks. In fact, acid catalysts can simultaneously catalyze both esterification and transesterification ${ }^{[13]}$. The common homogeneous acid catalysts are $\mathrm{H}_{2} \mathrm{SO}_{4}, \mathrm{HCl}, \mathrm{BF}_{3}, \mathrm{H}_{3} \mathrm{PO}_{4}$ and some organic sulfonic acids. Sulfonic and sulfuric acids are mostly preferred.

\subsubsection{Heterogeneous alkali and acid -catalyzed transesterification}

Although homogeneous catalysts showed greater performance toward transesterification to produce biodiesel, it also had some disadvantages such as high energy consumption, unwanted soap byproduct generated by reaction of the FFAs, expensive separation of the catalyst from the reaction mixture and large amount of wastewater during separation and purification. Heterogeneous catalysts can be separated more easily from reaction products, which may lead to lower biodiesel production costs due to the reuse of catalysts. Undesired saponification reactions could also be avoided by using heterogeneous acid catalysts.

Recently, applications of metal oxides ${ }^{[15]}$ or their composite materials, ion exchange resins ${ }^{[16]}$, magnetic nanoparticle catalysts ${ }^{[17]}$ and nano composite materials ${ }^{[18]}$ have been successively reported in the biodiesel production. Although the preparation of heterogeneous catalysts is complex, the application of heterogeneous catalysts might be an attractive solution for biodiesel production in the future.

\subsubsection{Enzymatic transesterification}

Chemical transesterification is widely applied to scale up 
the biodiesel production in industries. Compared to chemical approach, enzymatic approach offers more advantages such as less energy and water consumption, no pretreatments for high FFA feedstocks, easier product separation and glycerol recovery, and the absence of side reactions.

However, cost of lipase is the major issue for the industrialization of lipase mediated biodiesel production. In order to reduce the lipase cost, the following approaches could be adopted: (1) fermentation optimization; (2) super lipase development; and (3) enzyme immobilization for reuse.

\subsection{Engineering technologies}

\subsubsection{Supercritical and subcritical alcohol transesterification}

A supercritical fluid is a state of matter that's part way between a gas and liquid, which has good solubility and conductivity. Under supercritical conditions, transesterification reaction was completed in minutes, while the conventional catalytic transesterification takes several hours. Another positive effect of using supercritical conditions is that the alcohol is not only a reactant but also an acid catalyst ${ }^{[13]}$. In addition, it is easier to separate and purify the products by adjusting temperature and pressure. Supercritical alcohol transesterification has many advantages, but also has the drawbacks with high cost of apparatus and high energy consumption (high-temperature and high-pressure condition). How to lower the harsh reaction conditions to achieve industrial application has become a research hotspot. Co-solvents, such as carbon dioxide, hexane, diethyl ether, propane, tetrahydrofuran and subcritical alcohol with small amount of catalyst, added into the reaction mixture can effectively decrease the operating temperature, pressure and the amount of alcohol $^{[13]}$. Subcritical transesterification method is another effective way to reduce energy consumption. Encinar ${ }^{[19]}$ et al. (2012) used the subcritical alcohol transesterification method for biodiesel production and the results showed that the biodiesel yield of $99.9 \%$ could be obtained with reaction temperature $100{ }^{\circ} \mathrm{C}$, molar ratio of methanol to oil $12: 1$, and mass ratio of catalyst to oil of $0.7 \%$.

\subsubsection{Microwave assisted transesterification}

Different from conventional heating, microwave radiation generates heat through dipole rotation and ionic conduction. It has been widely demonstrated that microwave assisted transesterification offers a fast, easy route to produce biofuel with advantages of a short reaction time, a low oil/methanol ratio, an ease of operation a drastic reduction in the quantity of byproducts, and all with reduced energy consumption $^{[13,20,21]}$.

Although microwave assisted transesterification can provide higher activation energy and increase biodiesel yield, there are still technical barriers for industrialization. The most significant limitation of the scale up of this technology is the penetration depth of microwave radiation into the absorbing materials, which is only a few centimeters, depending on their dielectric properties. In addition, safety aspect is another reason why microwave reactors are rejected in industry ${ }^{[14]}$.

\subsubsection{Ultrasound assisted transesterification}

Ultrasound $(>20 \mathrm{kHz})$ alternately compresses and stretches the molecular spacing of the medium through which it passes, causing a series of compression and rarefaction cycles. Under high ultrasonic intensities, small cavities will grow rapidly, and bubbles will undergo sudden expansion and consequent collapse which breaks the stable phase boundary and generates the effect of stirring and mixing. Moreover, the instant collapse of cavitation bubbles could also generate free radicals (such as $\mathrm{H} \cdot \mathrm{HO} \cdot \mathrm{OH}_{2} \cdot$ ) which will accelerate the chemical reaction. Ultrasonic assisted transesterification method presents advantages such as more effective mixing, less solvent usage, shorter reaction time, and lower energy consumption. The application of ultrasound assisted transesterification technology also has the advantage of lower initial investment costs, better economic and environmental benefits ${ }^{[22]}$.

\section{Emissions characteristics}

\subsection{Carbon monoxide emission}

The general trend observed in most of the literatures was a decrease in $\mathrm{CO}$ emissions when substituting diesel with biodiesel and/or its blends. Previous studies ${ }^{[23,24]}$ summarized the emissions characteristics of some 2 nd biodiesels. The CO emissions of Jatropha curcas biodiesel, Pongamia pinnata biodiesel, Madhuca indica biodiesel, Hevea brasiliensis biodiesel and Pistacia chinensis biodiesel decreased by approximately $20-25 \%$, $4-46.5 \%, 26-58 \%, 1.13 \%-37.27 \%$ and $41 \%-60 \%$ in a high load condition, respectively ${ }^{[23-25]}$. However, the CO emissions of some other biodiesels ${ }^{[23,24,26]}$ are higher than that of petrodiesel such as Azadirachta indica biodiesel, Ceiba pentandra biodiesel, Calophyllum inophyllum biodiesel, and Simmondsia chinesis biodiesel.

In general, $\mathrm{CO}$ emissions are reduced in response to biodiesel inclusion owing to higher oxygen content and lower carbon to hydrogen ratio compared with diesel. However, some studies have the opposite conclusions which could be explained by the unfavorably higher viscosity and consequently less efficient atomization of these biodiesels. Moreover, there is a consensus that engine load has a significant effect on $\mathrm{CO}$ emission and higher engine speed has been associated with decreased $\mathrm{CO}$ emissions.

\subsection{Carbon dioxide emission}

$\mathrm{CO}_{2}$ is considered as a major GHG and the leading cause of global warming and clime change phenomena, therefore, many studies have focused on reducing $\mathrm{CO}_{2}$ emission from engines. Nevertheless, there exist the inconsistent conclusions in the published literatures 
regarding the impact of biodiesel on $\mathrm{CO}_{2}$ emissions. Some researches ${ }^{[26-29]}$ reported that the $\mathrm{CO}_{2}$ emissions reduced for Jatropha curcas biodiesel, Pongamia pinnata biodiesel, Hevea brasiliensis biodiesel, Ceiba pentandra biodiesel and Calophyllum inophyllum biodiesel due to the lower carbon to hydrocarbons ratio campared with petrodiesel. But some researches ${ }^{[30]}$ indicated that the $\mathrm{CO}_{2}$ emissions of biodiesels increased or kept similar because of the increase in the mass of fuel injected using the blend and better combustion with the fuel borne oxygen.

Of course, in the case of biodiesel, the higher $\mathrm{CO}_{2}$ emission don't cause more concern because of usage of biodiesels maintains the closed carbon cycle which does not raise the $\mathrm{CO}_{2}$ levels in the atmosphere.

\subsection{Nitrogen oxides emissions}

From the public health point of view, the $\mathrm{NO}_{\mathrm{x}}$ emission from diesel engines has become one of the most serious concerns. Although there is no consensus on $\mathrm{NO}_{\mathrm{x}}$ emissions in the literatures, most studies presented that the use of biodiesel would cause increases in $\mathrm{NO}_{\mathrm{x}}$ emissions. These previous studies ${ }^{[23,24,31]}$ showed that the $\mathrm{NO}_{\mathrm{x}}$ emissions of Pongamia pinnata biodiesel, Madhuca indica biodiesel, Calophyllum inophyllum biodiesel, Ceiba pentandra biodiesel, Simmondsia chinesis biodiesel and Annona squamosa biodiesel were 4.15-14.18\%, 6-16\%, $22.5 \%, 46.90 \%, 14-16 \%$ and $6.6 \%$ higher than that of petrodiesel, respectively.

The raw oils characteristics such as fatty acid composition could play an important role in $\mathrm{NO}_{\mathrm{x}}$ emissions. More specifically, higher content of unsaturated compounds could result in higher $\mathrm{NO}_{\mathrm{x}}$ emissions. The vast majority of the literature stated that $\mathrm{NO}_{\mathrm{x}}$ emissions increased with the increase of blending ratio of biodiesel in fuel blends. Higher cetane number of biodiesel has also been reported to result in increased $\mathrm{NO}_{\mathrm{x}}$ emissions. In addition, higher engine loads are associated with higher levels $\mathrm{NO}_{\mathrm{x}}$ emissions ${ }^{[2]}$.

\subsection{Unburnt hydrocarbon emission}

Photochemical smog is a serious threat to human respiratory system, which is generated through the reaction between gaseous $\mathrm{HC}$ and $\mathrm{NO}_{\mathrm{x}}$ in the sunlight. So, $\mathrm{HC}$ emission and its reduction strategy are of prominent importance. Many previous studies have reported significant reduction in $\mathrm{HC}$ emission from biodiesel compared to diesel, however a few reports ${ }^{[26,29]}$ presented the opposite conclusions. Such unexpected findings could be attributed to the higher viscosity of the oil feedstock and the resultant biodiesels. In general, the higher oxygen content and cetane number of biodiesel along with advanced injection and combustion timing significantly reduces $\mathrm{HC}$ emission for biodiese ${ }^{[32]}$. Further, engine operating conditions also affect $\mathrm{HC}$ emissions. At higher engine loads, the higher in-cylinder gas and exhaust gas temperatures are key factors leading to decreased formation of unburned $\mathrm{HC}$; less availability of oxygen under such circumstances may neutralize these positive effects though $^{[2]}$.

\subsection{Particulate matter emission}

Particulate matter (PM) can cause serious air pollution, and it is also considered to be one of the greatest threats to human health. The majority of studies indicated that the usage of biodiesel could effectively reduce PM emissions. There is a general positive correlation with reduction in PM emissions and biodiesel content in fuel blends. Using pure biodiesel can even significantly reduce $\mathrm{PM}$ emissions up to $50 \%{ }^{[2]}$. This could be well attributed to the oxygen content of biodiesel as well as the fact that biodiesel is free of aromatic and sulfur compounds. Moreover, the higher cetane number of biodiesel and the consequent improved combustion efficiency are also the reasons for the reductions in PM emissions. The influence of engine operating conditions is that higher engine loads will lead to inferior oxidation process and higher smoke emissions, and higher engine speeds are generally associated with improved combustion efficiency and consequently lower PM emissions.

\section{Conclusion}

Recently, biodiesel has become more attractive as its economic and environmental benefits. Compared with fossil diesel, biodiesel production and use have not only many advantages but also some drawbacks. Therefore, technological innovation, environmental protection and human health risks issues related to biodiesel production and use should be fully considered. Since the primary obstacle in commercial application of biodiesel is its high production cost, it is particularly important to replace currently used edible vegetable oils with non-edible woody oils or other cheaper oil feedstocks. The physicochemical properties of biodiesel are dependent upon the fatty acid composition and structure of the raw feedstocks and to some extent on the production process. On the industrial scale, biodiesel is still produced mainly by homogeneous catalytic transesterification. However, the innovative methods integrating catalytic technology and engineering technology are continuously being developed to improve biodiesel production process. Considering the great potential of biodiesel as a substitute for petrodiesel, its emission characteristics and environmental effects should also be emphasized. Neat biodiesel and its blends in various proportions reduced some pollutant emissions like $\mathrm{HC}, \mathrm{CO}$ and $\mathrm{PM}$ whereas it augmented the $\mathrm{NO}_{\mathrm{x}}$ emission. By using the post treatment technique of exhaust gas, $\mathrm{NO}_{\mathrm{x}}$ emission could be effectively reduced. In short, biodiesel is an environmental friendly alternative fuel and it has a broad application prospect under the background of the concept of "green, low-carbon and environmental protection" deeply rooted in people's hearts. Based on the discussion of the above sections, the following conclusions can be drawn.

(1) The fatty acid composition of oil feedstocks determine the biodiesel properties. The raw oils contained high percentages of monounsaturated fatty acid and low percentages of saturated fatty acid and 
polyunsaturated fatty acid could be seemed as ideal feedstocks for biodiesel production.

(2) Homogeneous transesterification is still considered to be the most typical and commercial method for biodiesel preparation. However, the innovative methods integrating catalytic technology and engineering technology are the trend for biodiesel production in the future.

(3) In most cases, the use of biodiesel can significantly reduce the $\mathrm{CO}, \mathrm{HC}$ and $\mathrm{PM}$ emissions.

\section{Reference}

1. M.M.K. Bhuiya, M.G. Rasul, M.M.K. Khan, et al., Renew. Sust. Energ. Rev. Prospects of 2nd generation biodiesel as a sustainable fuel-Part 2: Properties, performance and emission characteristics. 55, 11291146(2016)

2. H. Hosseinzadeh-Bandbafha, M. Tabatabaei, M. Aghbashlo, et al., Energy Conv. Manag. A comprehensive review on the environmental impacts of diesel/biodiesel additives. 174, 579-614(2018)

3. M.V. Kumar, A.V. Babu, P.R. Kumar. Eng. J. The impacts on combustion, performance and emissions of biodiesel by using additives in direct injection diesel engine. 57, 509-516(2018)

4. A. Demirbas. Energy Conv. Manag. Progress and recent trends in biodiesel fuels. 50(1), 14-34(2009)

5. M. Suresh, C.P. Jawahar, A. Richard. Renew. Sust. Energ. Rev. A review on biodiesel production, combustion, performance, and emission characteristics of non-edible oils in variable compression ratio diesel engine using biodiesel and its blends. 92, 38-49(2018)

6. S.B. Živković, M.V. Veljković, I.B. Banković-Ilić, et al., Renew. Sust. Energ. Rev. Technological, technical, economic, environmental, social, human health risk, toxicological and policy considerations of biodiesel production and use. 79, 222-247(2017)

7. Y.Q. Zhang, L.M. Jia, Z.G. Chen, et al., China Oils Fats. Development of new non-food woody oil-plant resources and comparative analysis of biodiesel properties. 41(12), 1-8(2016)

8. M. Chakraborty, D.C. Baruah. Fuel Process. Technol. Investigation of oxidation stability of Terminalia belerica biodiesel and its blends with petrodiesel. 98, 51-58(2012)

9. Y.Q. Zhang, L. Jin, J. Duan, et al., Forests. The assessment of two species of soapberry as resources for high-quality biodiesel production with an optimized method of ultrasound-assisted oil extraction. 11, 212(2020)

10. L. Wang, H. Yu, X. He. J. Fuel Chem. Technol. Influence of fatty acid composition of woody biodiesel plants on the fuel properties. 40(4), 397-404(2012)

11. O.K. Iha, F.C.S.C. Alves, P.A.Z. Suarez. Ind. Crop. Prod. Potential application of Terminalia catappa L. and Carapa guianensis oils for biofuel production: Physical-chemical properties of neat vegetable oils, their methyl-esters and bio-oils (hydrocarbons). 52, 95-98(2014)
12. H.K. Suh, C.S. Lee. Renew. Sust. Energ. Rev. A review on atomization and exhaust emissions of a biodiesel-fueled compression ignition engine. 58, 1601-1620(2016)

13. A.P. Vyas, J.L. Verma, N. Subrahmanyam. Fuel. A review on FAME production processes. 89, 19(2010)

14. B. Bharathiraja, M. Chakravarthy, R.R. Kumar, et al., Renew. Sust. Energ. Rev. Biodiesel production using chemical and biological methods - A review of process, catalyst, acyl acceptor, source and process variables. 38, 368-382(2014)

15. G. Chen, R. Shan, S. Li, et al., Fuel. A biomimetic silicification approach to synthesize $\mathrm{CaO}-\mathrm{SiO}_{2}$ catalyst for the transesterification of palm oil into biodiesel. 153, 48-55(2015)

16. J. Li, Y. Fu, X. Qu, et al., Bioresour. Technol. Biodiesel production from yellow horn (Xanthoceras sorbifolia Bunge.) seed oil using ion exchange resin as heterogeneous catalyst. 108, 112-118(2012)

17. Y. Liu, P. Zhang, M. Fan, et al., Fuel. Biodiesel production from soybean oil catalyzed by magnetic nanoparticle $\mathrm{MgFe}_{2} \mathrm{O}_{4} @ \mathrm{CaO} .164,314-321(2016)$

18. Y.T. Wang, Z. Fang, F. Zhang, et al., Bioresour. Technol. One-step production of biodiesel from oils with high acid value by activated $\mathrm{Mg}$-Al hydrotalcite nanoparticles. 193, 84-89(2015)

19. J.M. Encinar, A. Pardal, G. Martínez. Fuel Process. Technol. Transesterification of rapeseed oil in subcritical methanol conditions. 94, 40-46(2012)

20. R. Kumar, G.R. Kumar, N. Chandrashekar. Bioresour. Technol. Microwave assisted alkali-catalyzed transesterification of Pongamia pinnata seed oil for biodiesel production. 102, 6617-6620(2011)

21. S. Wahidin, A. Idris, S.R.M. Shaleh. Bioresour. Technol. Ionic liquid as a promising biobased green solvent in combination with microwave irradiation for direct biodiesel production. 206, 150-154(2016)

22. B. Karmakar, G. Halder. Energy Conv. Manag. Progress and future of biodiesel synthesis: Advancements in oil extraction and conversion technologies. 182, 307-339(2019)

23. A.M. Ashraful, H.H. Masjuki, M.A. Kalam, et al., Energy Conv. Manag. Production and comparison of fuel properties, engine performance, and emission characteristics of biodiesel from various non-edible vegetable oils: A review. 80, 202-228(2014)

24. P. Tamilselvan, N. Nallusamy, S. Rajkumar. Renew. Sust. Energy. Rev. A comprehensive review on performance, combustion and emission characteristics of biodiesel fuelled diesel engines. 79, 1134-1159(2017)

25. P. Tamilselvan, N. Nallusamy, S. Rajkumar. Renew. Sust. Energy. Rev. A comprehensive review on performance, combustion and emission characteristics of biodiesel fuelled diesel engines. 79, 1134-1159(2017)

26. H.C. Ong, H.H. Masjuki, T.M.I. Mahlia, et al., 
Energy. Engine performance and emissions using Jatropha curcas, Ceiba pentandra and Calophyllum inophyllum biodiesel in a CI diesel engine. 69, 427445(2014)

27. A.M. Liaquat, H.H. Masjukia, M.A. Kalam, et al., Energy Procedia. Application of blend fuels in a diesel engine. 14, 1124-1133(2012)

28. S. Jindal, B.P. Nandwana, N.S. Rathore. Energy Fuels. Comparative evaluation of combustion, performance, and emissions of jatropha methyl ester and karanj methyl ester in a direct injection diesel engine. 24(3), 1565-1572(2010)

29. D. Visha, S. Dubey, R. Goyal, et al., Renew. Energy. Optimization of alkali-catalyzed transesterification of rubber oil for biodiesel production \& its impact on engine performance. 158, 167-180(2020)

30. A. Sanjid, M.A. Kalam, H.H. Masjuki, et al., J. Clean Prod. Performance and emission of multi-cylinder diesel engine using biodiesel blends obtained from mixed inedible feedstocks. 112, 4114-4122(2016)

31. P.K. Sahoo, L.M. Das, M.K.G. Babu, et al., Fuel. Comparative evaluation of performance and emission characteristics of jatropha, karanja and polanga based biodiesel as fuel in a tractor engine. 88, 16981707(2009)

32. N. Kumar, Varun, S.R. Chauhan. Renew. Sust. Energ. Rev. Performance and emission characteristics of biodiesel from different origins: A review. 21, 633658(2013) 